\title{
Kappa Opioid Receptor Activation Potentiates the Cocaine-Induced Increase in Evoked Dopamine Release Recorded In Vivo in the Mouse Nucleus Accumbens
}

\author{
Jonathan M Ehrich ${ }^{1,2}$, Paul EM Phillips',2,3 and Charles Chavkin*,1,2 \\ 'Graduate Program in Neurobiology and Behavior, University of Washington School of Medicine, Seattle, WA, USA; ${ }^{2}$ Department of \\ Pharmacology, University of Washington School of Medicine, Seattle, WA, USA; ${ }^{3}$ Department of Psychiatry and Behavioral Sciences, University of \\ Washington School of Medicine, Seattle, WA, USA
}

\begin{abstract}
Behavioral stressors increase addiction risk in humans and increase the rewarding valence of drugs of abuse including cocaine, nicotine and ethanol in animal models. Prior studies have established that this potentiation of drug reward was mediated by stress-induced release of the endogenous dynorphin opioids and subsequent kappa opioid receptor (KOR) activation. In this study, we used in vivo fast scan cyclic voltammetry to test the hypothesis that KOR activation before cocaine administration might potentiate the evoked release of dopamine from ventral tegmental (VTA) synaptic inputs to the nucleus accumbens (NAc) and thereby increase the rewarding valence of cocaine. The KOR agonist U50488 inhibited dopamine release evoked by either medial forebrain bundle (MFB) or pedunculopontine tegmental nucleus (PPTg) activation of VTA inputs to the shell or core of the mouse NAc. Cocaine administration increased the dopamine response recorded in either the shell or core evoked by either MFB or PPTg stimulation. Administration of U50488 I5 min before cocaine blocked the conditioned place preference (CPP) to cocaine, but only significantly reduced the effect of cocaine on the dopamine response evoked by PPTg stimulation to NAc core. In contrast, administration of U50488 60 min before cocaine significantly potentiated cocaine CPP and significantly increased the effects of cocaine on the dopamine response evoked by either MFB or PPTg stimulation, recorded in either NAc shell or core. Results of this study support the concept that stress-induced activation of KOR by endogenous dynorphin opioids may enhance the rewarding valence of drugs of abuse by potentiating the evoked dopamine response. Neuropsychopharmacology (2014) 39, 3036-3048; doi:I0.I038/npp.20I4.I57; published online 23 July 20I4
\end{abstract}

\section{INTRODUCTION}

In humans, uncontrolled stress exposure has been shown to increase vulnerability to drug abuse, with stress levels showing positive associations with alcohol consumption (DeFrank et al, 1987) escalation of nicotine use, and increased alcohol consumption (Miller et al, 1974; Pomerleau and Pomerleau, 1987). In animal models, acute stress exposure also leads to elevated self-administration of amphetamine (Piazza et al, 1990) and cocaine (Goeders and Guerin, 1994). Neuroendocrine mediators of the stress response including corticotropin-releasing factor and glucocorticoids have been implicated in stress-induced reinstatement (Mantsch et al, 2014; Wise and Morales, 2010). In addition, a specific role of the dynorphin/kappa opioid receptor (KOR) system in stress-induced dysphoria and anxiety responses underlying the pro-addictive effects of stress has been suggested by antagonism or genetic

*Correspondence: Dr C Chavkin, Department of Pharmacology, University of Washington School of Medicine, PO Box 357280, Seattle, WA 98195, USA, Tel: +I 206543 4266, Fax: + I 206685 3822, E-mail: cchavkin@u.washington.edu

Received 3 March 20I4; revised 5 June 2014; accepted 25 June 20।4; accepted article preview online 27 June 2014 disruption of the dynorphin/KOR system (Bruijnzeel, 2009; Knoll and Carlezon, 2010; Tejeda et al, 2012). For example, the ability of stress exposure to potentiate both cocaine reward and nicotine reward in the conditioned place preference (CPP) paradigm was found to be blocked by the KOR antagonist norbinaltorphimine and required the expression of both dynorphin and KOR (McLaughlin et al, 2003; Schindler et al, 2010; Smith et al, 2012). Initially, the observation that KOR activation could potentiate the rewarding properties of drugs of abuse was surprising because co-administration of KOR agonists block the rewardsensitizing properties of cocaine (Shippenberg et al, 1996) and cocaine-induced reduction of ICSS thresholds (Tomasiewicz et al, 2008). Furthermore, KOR agonists inhibit dopamine release and produce aversive behavioral responses ( $\mathrm{Di}$, Chiara and Imperato, 1988; Shippenberg and Herz, 1988).

This apparent contradiction was rationalized by proposing that the dysphoric effects of KOR activation could produce aversion and block reward when paired directly with administration of a euphorigenic drug of abuse, but the magnitude of drug reward would be potentiated if it were experienced while the subject was in a dynorphin/KORinduced dysphoric state (Bruchas et al, 2010). In support of this hypothesis, pretreatment with the KOR agonist U50488 
$60 \mathrm{~min}$ before cocaine potentiated its rewarding properties in a manner similar to that seen after repeated stress exposure; whereas pretreatment with U50488 15 min before cocaine blocked cocaine reward (Figure 1a; McLaughlin et al, 2006).
The prevailing view is that the dysphoric effects of aversive drugs result from inhibition of dopamine release from the ventral tegmental area (VTA) inputs to the nucleus accumbens (NAc; Carroll and Carlezon, 2013; Shippenberg et al, 2001), via activation of KOR on dopaminergic nerve a

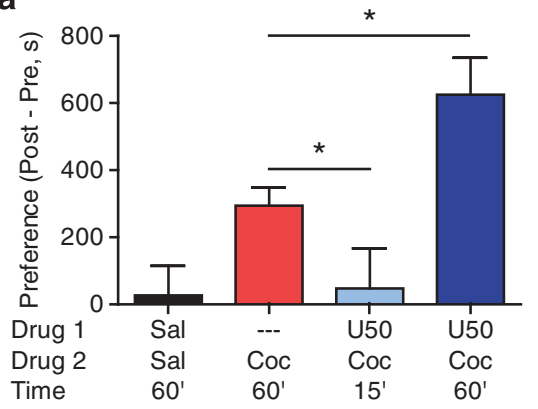

C

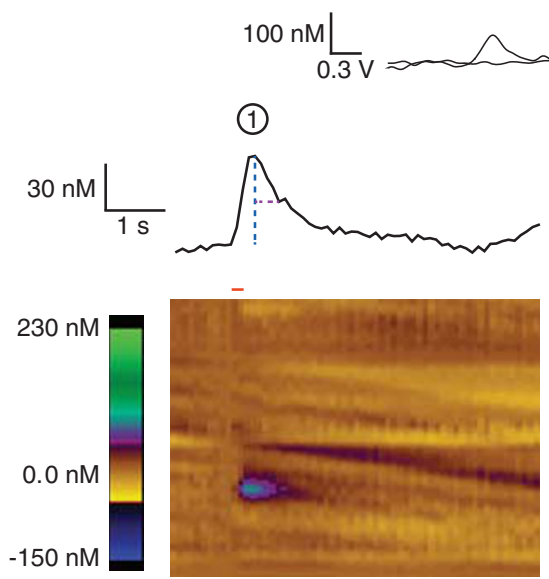

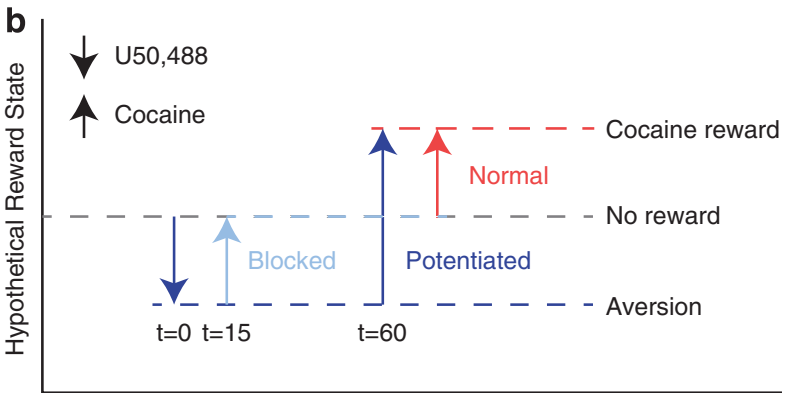

60 min post-U50,488

60 min post-cocaine

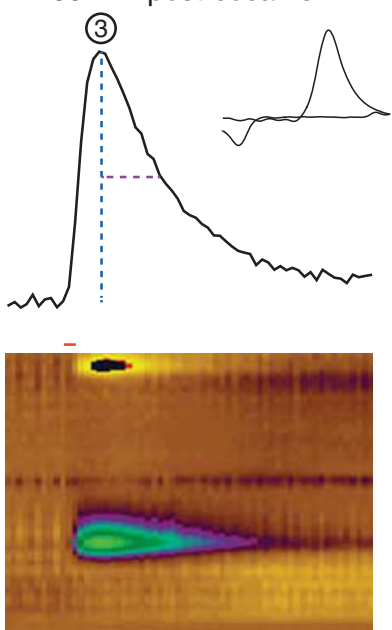

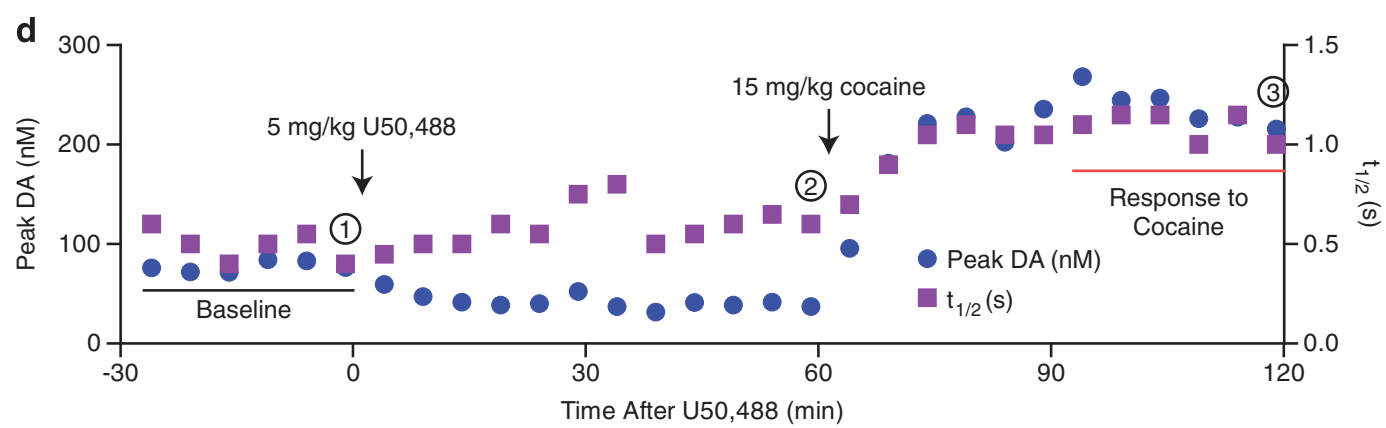

Figure I Kappa opioid receptor activation affects cocaine reward and dopamine responses in a time-dependent manner. (a) Preference scores for animals receiving cocaine after no pretreatment or after pretreatment with U50488 either 15 or 60 min prior shows the ability of KOR activation to either block or potentiate cocaine reward depending on time of pretreatment. Modified from McLaughlin 2003. Error bars represent SEM. (b) A conceptual model to explain the behavioral results depicted in a. If cocaine and KOR agonist are co-administered at close time points (20 min or less), then KOR agonistinduced decreases in reward state ('Aversion') and cocaine-induced increases in reward state simultaneously co-occur and thus lead to a mutual block of preference and aversion ('Blocked'/'No reward'). At longer pretreatment time points, KOR agonist-induced dysphoria leads to a re-setting of the animal's internal reward state. When cocaine is then administered ('Cocaine reward'), it leads to a subjectively greater experience of reward ('Potentiated,' relative to saline-pretreated controls, 'Normal') even if the absolute magnitude of the reward state experienced after cocaine is unchanged. (c) Representative images showing analysis of FSCV data at baseline, after administration of U50488, and after subsequent administration of cocaine. Bottom: color plots showing current generated by oxidation and reduction at the site of the working electrode during application of the triangle wave form. Red line shows time of MFB stimulation (six pulses at $30 \mathrm{~Hz}, 300 \mu \mathrm{A}$ ). Middle: current by time plot shows evoked dopamine release (peak amplitude marked in blue) and uptake (half-life marked in purple). Scale bars mark $30 \mathrm{nM}$ dopamine and I s. Top: the cyclic voltammagram from the time of peak current confirms that the recorded current is induced by oxidation and reduction of dopamine. Scale bars mark $100 \mathrm{nM}$ dopamine and $0.3 \mathrm{~V}$ from applied waveform. (d) Representative data from the entire recording of the animal are shown. Blue circles show change in the peak amplitude of the evoked dopamine current over time after administration of U50488 (after $t=0$ as marked) and cocaine (after $t=60$ as marked). Purple squares show the half-life of evoked dopamine for each recording. Data shown in $\mathrm{c}$ are taken from time points I, 2, and 3 as labeled. 
terminals (Tejeda et al, 2012). The ability of KOR agonists to induce aversion has been shown to require activation of D1 receptors in the NAc, and it is blocked by selective lesioning of mesolimbic but not nigrostriatal dopamine neurons (Shippenberg et al, 1993). Intriguingly, although both intra-NAc and intra-VTA microinjection of U50488 in rat result in conditioned place aversion (Bals-Kubik et al, 1993), intra-NAc but not intra-VTA injection of KOR agonists induce a reduction in NAc dopamine (Devine et al, 1993; Margolis et al, 2006; Spanagel et al, 1992). This failure of intra-VTA KOR agonist administration to alter NAc dopamine levels has been attributed to the observation that in rat, medial prefrontal cortex-projecting but not NAc-projecting dopaminergic neurons show direct inhibition after administration of the KOR agonist U69593 (Margolis et al, 2006). Based on this result, it has been proposed that NAc-projecting neurons express functional KOR exclusively on terminals, whereas medial prefrontal cortex-projecting neurons express KOR in both terminal and somatodendritic compartments (Margolis et al, 2006; Tejeda et al, 2013). However, in mouse it has been shown that U69593 can directly inhibit NAc-projecting dopaminergic neurons (Ford et al, 2006). The discrepant results of these experiments may be due to a species difference or some other experimental factor. As such, it is not clear if KOR activation in the terminal and somatodendritic compartments can separately regulate NAc dopamine signaling in mice.

If the dysphoric actions of KOR are mediated by presynaptic inhibition of dopamine release, then the potentiation of cocaine reward resulting in enhanced CPP might be evident in the interactions controlling accumbal dopamine levels. In this model (Figure 1b), KOR agonist pretreatment at short pretreatment times ( $15 \mathrm{~min}$ or less) would be predicted to block cocaine reward by cancelling cocaineinduced effects on dopamine signaling. At longer pretreatment times, reduced dopamine release effectively resets the baseline, allowing an increased behavioral response to cocaine caused by the increased elevation of dopamine levels relative to this modified baseline. In the present study, we tested this model using fast-scan cyclic voltammetry (FSCV) to measure evoked dopamine release in the core or shell of the NAc following medial forebrain bundle (MFB) or pedunculopontine tegmental nucleus (PPTg) stimulation, which stimulate dopaminergic axons directly or excitatory afferents to the VTA (Floresco et al, 2003; Zweifel et al, 2009).

\section{MATERIALS AND METHODS \\ CPP}

Male C57Bl/6 wild-type mice were used in place-conditioning studies, as previously described (McLaughlin et al, 2003). Mice were placed in a three-chamber box before any treatment and allowed to freely explore. After two intervening days of treatment with saline, U50488 (5 mg/kg, i.p.), and/or cocaine $(15 \mathrm{mg} / \mathrm{kg}$, s.c.) in one chamber and saline in the other, on the fourth day, mice were again allowed to freely explore the chamber. The difference in time spent in the drug-paired chamber on the pre- and post-training test days was recorded as the place preference.

\section{In vivo $\mathrm{FSCV}$}

Male C57Bl/6 wild-type mice were anesthetized with $1.5 \mathrm{~g} / \mathrm{kg}$ urethane. Sixty minutes later, anesthesia was confirmed and mice were mounted on a Model 900 stereotaxic alignment system (David Kopf Instruments). Carbon fiber (grade 34700; Goodfellow Corporation) was pulled through a glass pipette using a Sutter P-97 puller to form a microelectrode. The fiber was then cut to approximately $120-140 \mu \mathrm{m}$ past the glass seal. To detect dopamine, the potential at the working electrode was held at $-0.4 \mathrm{~V}$ vs an $\mathrm{Ag} / \mathrm{AgCl}$ reference electrode, then ramped to $+1.3 \mathrm{~V}$ and then back to $-0.4 \mathrm{~V}$ at $400 \mathrm{~V} / \mathrm{s}$. This waveform was applied at a rate of $10 \mathrm{~Hz}$. Carbon fiber microelectrodes were implanted in the NAc $(A / P=+1.52 \mathrm{~mm}, M / L=+/-1.15 \mathrm{~mm}, D / V=-3.9-4.1$ (core) or $-4.2-4.4$ (shell) from bregma) and the reference electrode was implanted in contralateral cortex. Bipolar parallel stimulation electrodes (Plastics One; Roanoke, VA) were implanted either in the $\operatorname{MFB}(A / P=-2.40 \mathrm{~mm}$, $M / L= \pm 1.10 \mathrm{~mm}, D / V=-4.5-5.20 \mathrm{~mm}$ from bregma) or the PPTg $(A / P=-0.68 \mathrm{~mm}$ from lambda, $M / L= \pm 0.70 \mathrm{~mm}$, $D / V=-2.50-3.20 \mathrm{~mm}$ from bregma).

\section{Electrode Calibrations}

Electrodes were calibrated by recording the in vitro response to an injection of $1 \mu \mathrm{M}$ dopamine in aCSF. For each electrode, this was performed three times and the result was averaged. The average of all of these calibrations $(61.4 \mathrm{nA}$ current per $1 \mu \mathrm{M}$ dopamine, data not shown) was used to convert current to dopamine concentration.

\section{Histology and Confirmation of Recording Sites}

At the end of each experiment, urethane $(0.5 \mathrm{ml}$ of $0.15 \mathrm{~g} / \mathrm{ml})$ was injected into the mouse before inducing a lesion at the site of the working electrode and, in a subset of animals, the lateral pole of the stimulating electrode. The mouse was then intracardially perfused with ice-cold PBS and $4 \%$ paraformaldehyde, and the brain was removed. After cryoprotection with $30 \%$ sucrose, brains were sliced at $40 \mu \mathrm{m}$ and then stained with cresyl violet to identify the recording site (Supplementary Figure 1) and the stimulation site (Supplementary Figure 2). Recording position was also verified by measuring the change in evoked response as the electrode tip was lowered through the anterior commissure (Supplementary Figure 3). Data were excluded from the subsequent analysis if a lesion was not clearly present in the core or shell and the anterior commissure was not found during positioning of the working electrode. Similarly, data were excluded from subsequent analysis if stimulation lesions or stimulation electrode tracks were found not to be in the vicinity of the PPTg.

\section{Stimulus Parameters}

A series of pilot experiments were performed utilizing sweeps of varying stimulus intensities to optimize the recording parameters in both shell and core (Supplementary Figures 3-6). A pulse width of $4.0 \mathrm{~ms}$ was used for all stimuli performed throughout all experiments. Varying the current intensity, the number of applied pulses, and the 
stimulation frequency applied to the MFB affected the amplitude of the evoked responses recorded in shell and core, and there was no significant difference in sensitivity between the two recording sites (Supplementary Figure 4A-C). Varying the stimulation parameters applied to the PPTg also affected the amplitude of the evoked dopamine responses recorded in shell and core, however, the amplitude of the evoked response was significantly smaller in core than shell (Supplementary Figure 4D-F). Furthermore, the stimulus required to evoke half-maximal response was significantly smaller following PPTg stimulation than MFB (Supplementary Figure 4G-I). U50488 (5 mg/kg, i.p.) significantly reduced the dopamine response evoked by MFB stimulation at each of the current intensities $100-400 \mu \mathrm{A}$, applied pulse numbers $\geqslant 20$, and stimulus frequencies $\geqslant 40 \mathrm{~Hz}$ (Supplementary Figure $5 \mathrm{~A}-\mathrm{C}$ ). Although a main inhibitory effect of U50488 was observed in each case, a significant interaction was also observed for each stimulus parameter, indicating that for MFB-evoked dopamine the effect of KOR activation varied as stimulus parameters were varied (Supplementary Figures 5A, 4C, and 4D). A subsequent analysis revealed that the stimulus current required to evoke the half-maximal response was also significantly increased after U50488 administration (Supplementary Figure 5B). As a result, for MFB experiments, stimulus parameters of six pulses at $30 \mathrm{~Hz}$ and $300 \mu \mathrm{A}$ were chosen to reflect the physiological burst-firing pattern of a dopaminergic neuron (Hyland et al, 2002). Parallel analysis of U50488 effects on PPTg stimulated responses also showed a main inhibitory effect of U50488 in each case; however, a significant interaction was only observed for stimulus duration (Supplementary Figure 6A-C). Follow-up analysis revealed that U50488 administration did not significantly affect the stimulus required to evoke the half-maximal response to PPTg stimulation (Supplementary Figure 6D-F). We next analyzed the effects of cocaine administration on PPTg-stimulated dopamine across different stimulus parameters (Supplementary Figure 7). The ability of cocaine to increase terminal dopamine concentrations was demonstrated by a main effect of cocaine administration for varying stimulus durations and frequencies; however, an interaction was again only observed for stimulus duration (Supplementary Figure 7A and B). Follow-up analysis revealed that cocaine administration did not significantly affect the stimulus required to evoke the half-maximal response to PPTg stimulation (Supplementary Figure 7C and D). Based on this analysis, we chose a set of PPTg stimulation parameters able to produce stable and significant responses to U50488 and cocaine (30 pulses at $60 \mathrm{~Hz}$ and $150 \mu \mathrm{A}$, applied every $300 \mathrm{~s}$ ). These PPTg stimuli evoked similar levels of dopamine release to that evoked by the MFB stimulation parameters (Supplementary Figure 8).

\section{Drugs}

$( \pm) \mathrm{U} 50488 \mathrm{H}$ and cocaine hydrochloride were provided by the National Institute of Drug Abuse Drug Supply Program. Urethane was obtained from Sigma-Aldrich (St Louis, MO). All drugs were dissolved in sterile saline for use in vivo.

\section{FSCV Data Collection}

Experiments begin with $60 \mathrm{~min}$ of stimulation every $300 \mathrm{~s}$. The recordings from the last six of these stimuli were averaged together to form a baseline. As illustrated in Figure 1d, after a stable baseline of dopamine responses was established, mice were injected with either saline or U50488 $(5 \mathrm{mg} / \mathrm{kg}$, i.p.). Then $15 \mathrm{~min}$ later, one group of mice received an injection of cocaine $(15 \mathrm{mg} / \mathrm{kg}$, s.c.; the U50488 15 min pretreatment group). The other three groups of mice received injections of saline or cocaine $60 \mathrm{~min}$ after the first injection. For experiments analyzing interactions between U50488 and cocaine, the last six stimuli before the first injection were averaged together to form the first baseline. The response to cocaine was determined by averaging across the six stimuli comprising the period from 35 to $60 \mathrm{~min}$ after cocaine injection or the second saline injection. The response to U50488 (data collected only from animals receiving U50488 $60 \mathrm{~min}$ before cocaine) was determined by averaging across the six stimuli comprising the period from 35 to 60 min after U50488 injection. The acute response to cocaine or saline (\%2nd baseline dopamine) was calculated using an alternate baseline comprising the six stimuli collected before the last injection. For MFB experiments, dopamine clearance rate was estimated as $t_{1 / 2}$, which is the time for the dopamine current to recover to half of peak.

A follow-up experiment was performed to determine how reducing stimulation intensity of PPTg affected cocaineinduced increases in the dopamine response recorded in the NAc core. For this experiment, after the recording and stimulation electrodes were lowered to their final locations, two sweeps of stimulus current intensity were performed in $25 \mu \mathrm{A}$ increments, from 0 to $150 \mu \mathrm{A}$, first in an ascending then descending intensity. Duration was set at 30 pulses and frequency at $60 \mathrm{~Hz}$. The results of these two sweeps were averaged together and the stimulus current at which the [DA] evoked was half of that evoked by $150 \mu \mathrm{A}$ was determined. The recordings then began with a stimulus of 30 pulses at $60 \mathrm{~Hz}$ and $150 \mu \mathrm{A}$ until baseline was recorded as in other experiments. After baseline was reached, stimulus current was changed to the previously determined reduced current. Recordings then continued as normal, with cocaine administered $60 \mathrm{~min}$ after switching to the reduced current and recordings continuing for another $60 \mathrm{~min}$. Data were analyzed as in other experiments.

\section{Analysis}

Data were compiled in Microsoft Excel and statistical analyses were performed using Prism 5.01 for Windows (GraphPad, San Diego, CA). Dopamine concentrations were determined by recording the peak current within $1 \mathrm{~s}$ of the termination of electric stimulation and calibrating as described above. FSCV data were analyzed using linear regression, $t$-test, one-way ANOVA, two-way ANOVA, and two-way repeated-measures ANOVA as described in the text. Because $t_{1 / 2}$ data were nonparameteric, no analysis was performed on raw $t_{1 / 2}$ data. Instead, the arithmetic shift between baseline $t_{1 / 2}$ and $t_{1 / 2}$ after drug administration was analyzed. This was found to pass a Kolmogorov-Smirnov normality test in 15 out of 16 cases $(P>0.05)$. When 
ANOVA found significant results, Bonferroni post-hoc analyses were applied where appropriate; in certain cases, Bonferroni post-hoc analysis was applied after no interaction was seen to confirm negative results. Data are presented as mean \pm SEM. Significance was placed at $P<0.05$.

\section{RESULTS}

Prior studies have shown that kappa receptor agonists can inhibit cocaine reward measured in rodents either by CPP or self-administration methods (McLaughlin et al, 2006; Schenk et al, 1999). An example of that result is shown (Figure 1a) where the kappa agonist U50488 (5 mg/kg) administered $15 \mathrm{~min}$ before cocaine $(15 \mathrm{mg} / \mathrm{kg})$ significantly reduced the CPP of male $\mathrm{C} 57 \mathrm{Bl} / 6$ mice. In contrast, U50 488 administered 60 min before cocaine resulted in a significant potentiation of the subsequent cocaine-CPP (McLaughlin et al, 2006; Figure 1a). We rationalize this KOR-induced potentiation of cocaine $\mathrm{CPP}$ as a consequence of KORinduced dysphoria leading to an increased magnitude of cocaine reward (Figure 1b; Bruchas et al, 2010). One mechanism of this interaction could be if prior treatment with KOR agonist caused an increase in the effects of cocaine on dopamine release in the NAc, but another could be that cocaine-induced increases in dopamine are proportionately larger after inhibition by KOR agonist. To test this model, we measured dopamine release in anesthetized mice using FSCV. As shown in Figure 1c, stimulation of the MFB (6 pulses, $30 \mathrm{~Hz}, 300 \mu \mathrm{A}$ ) evoked a stereotyped cyclic voltammagram typical of dopamine (inset and colorplot Figure 1c). The peak amplitude of the evoked current

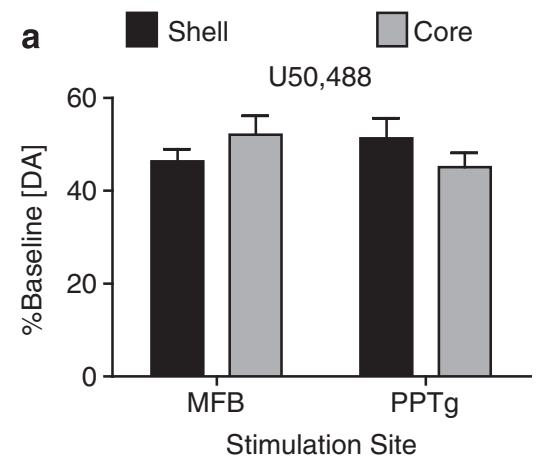

b

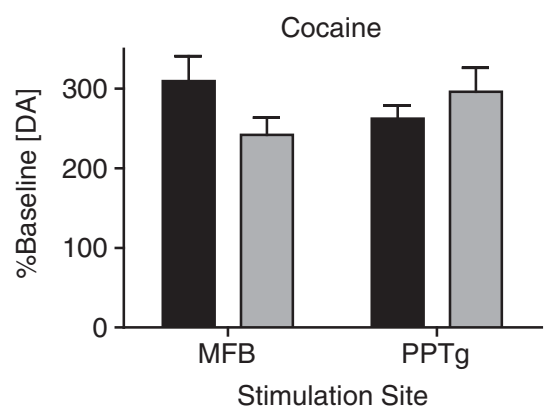

Figure 2 The dopaminergic response to U50488 alone and cocaine alone is consistent across stimulation and recording sites. (a) The response to U50488 (shown as percent baseline [DA]) in animals injected with U50488 60 min before cocaine shows that administration of U50488 uniformly inhibits dopamine release in the NAc regardless of recording site (core vs shell) or stimulation site (MFB vs PPTg; $n=6-9$ ). (b) The response to cocaine (shown as percent baseline $[D A])$ in animals injected with saline 60 min before cocaine shows that administration of cocaine uniformly elevates dopamine in the NAc regardless of recording site (core vs shell) or stimulation site (MFB vs PPTg; $n=6-9$ ). Error bars represent SEM.

Figure 3 The effects of KOR activation on the dopaminergic response to cocaine at different pretreatment time points are differentially regulated depending on recording site and stimulation site. (a) Diagram showing time points of treatment for each experiment. Stimulations occurred every 5 min as marked by vertical lines. The average of the first six stimulations ( $0-25$ min before the first injection) was used as baseline for this figure; the average of the six stimulations comprising the period from 35 to $60 \mathrm{~min}$ after the second injection were used as the response to cocaine or saline. (b) Cartoon depicting stimulation of MFB and recording of dopamine released in NAc shell. (c) Timeline of MFB-evoked dopamine release recorded from the NAc shell from all groups; showing responses to saline, U50488 (5 mg/kg i.p.), and/or cocaine (I $5 \mathrm{mg} / \mathrm{kg}$ s.c.). Administration of U50488 induced an inhibition of dopamine release in both groups, and administration of cocaine consistently elevated dopamine levels $(n=4-8)$. (d) The response of MFB-evoked dopamine recorded from the NAc shell to cocaine or saline from all four groups, shown as averaged evoked dopamine currents. Red bar marks time of stimulation. U50488 pretreatment significantly inhibited the response to cocaine in a time-independent manner relative to saline-pretreated animals; however, cocaine still elevated dopamine to levels greater than those recorded from animals treated with saline alone $(n=4-8)$. (e) Cartoon depicting stimulation of MFB and recording of dopamine released in NAc core. ( $f$ ) Timeline of MFB-evoked dopamine release recorded from the NAc core from all groups; showing responses to saline, U50488 (5 mg/kg i.p.) and/or cocaine (I $5 \mathrm{mg} / \mathrm{kg}$ s.c.). Administration of U50488 inhibited dopamine release in both groups, and administration of cocaine consistently elevated dopamine levels $(n=7-9)$. (g) The response of MFB-evoked dopamine recorded from the NAc core to cocaine or saline from all four groups, shown as averaged evoked dopamine currents. U50488 pretreatment failed to alter the response to cocaine relative to saline-pretreated animals ( $n=7-9)$. (h) Cartoon depicting stimulation of PPTg and recording of dopamine released in NAc shell. (i) Timeline of PPTgevoked dopamine release recorded from the NAc shell from all groups; showing responses to saline, U50488 (5 mg/kg i.p.), and/or cocaine (I5 mg/kg s.c.). Administration of U50488 inhibited dopamine release in both groups, and administration of cocaine consistently elevated dopamine levels $(n=7-9)$. (j) The response of PPTg-evoked dopamine recorded from the NAc shell to cocaine or saline from all four groups, shown as averaged evoked dopamine currents. U50488 pretreatment at 15 min significantly inhibited the response to cocaine, whereas U50488 at 60 min shows a trend toward an inhibited response to cocaine; in both cases relative to saline-pretreated animals. In all animals receiving cocaine, dopamine levels were elevated to an extent greater than that recorded from animals treated with saline alone $(n=7-9)$. ( $(k)$ Cartoon depicting stimulation of PPTg and recording of dopamine released in NAc core. (I) Timeline of PPTg-evoked dopamine release recorded from the NAc core from all groups; showing responses to saline, U50488 (5 mg/kg i.p.), and/or cocaine ( $15 \mathrm{mg} / \mathrm{kg}$ s.c.). Administration of U50488 inhibited dopamine release in both groups, and administration of cocaine consistently elevated dopamine levels $(n=6-8)$. (m) The response of PPTg-evoked dopamine recorded from the NAc core to cocaine or saline from all four groups, shown as averaged evoked dopamine currents. U50488 pretreatment at 15 min significantly inhibits the response to cocaine relative to both saline-pretreated animals and animals receiving U50488 pretreatment at 60 min; further, cocaine after 15 min pretreatment with U50488 failed to significantly alter dopamine levels relative to animals treated with saline alone. By contrast, U50488 pretreatment at $60 \mathrm{~min}$ failed to alter the response to cocaine relative to saline-pretreated animals, whereas elevating dopamine to levels significantly greater than those recorded from animals treated with saline alone $(n=6-8)$. Error bars represent SEM. 
recorded using a calibrated carbon fiber electrode in the NAc core is shown. KOR activation by U50488 ( $5 \mathrm{mg} / \mathrm{kg}$ i.p.) reduced amplitude of the evoked response, whereas cocaine $(15 \mathrm{mg} / \mathrm{kg}$ s.c.) increased the amplitude and slowed the clearance, measured as $t_{1 / 2}$ (Figure 1c). These doses were the same as those used in the CPP drug interaction study (Figure 1a). In a representative experiment, evoked responses were measured every $300 \mathrm{~s}$. After establishing a stable baseline, U50488 was injected and the time course of response was recorded. Subsequent administration of cocaine increased the evoked dopamine response and the $t_{1 / 2}$ (Figure 1d).

\section{Basal Responses Are Consistent Across Stimulation and Recording Sites}

In this series of experiments, we stimulated either the MFB or PPTg and measured evoked responses in either the NAc core or the shell. Stimulation of MFB directly drives release at dopamine terminals, whereas PPTg stimulation
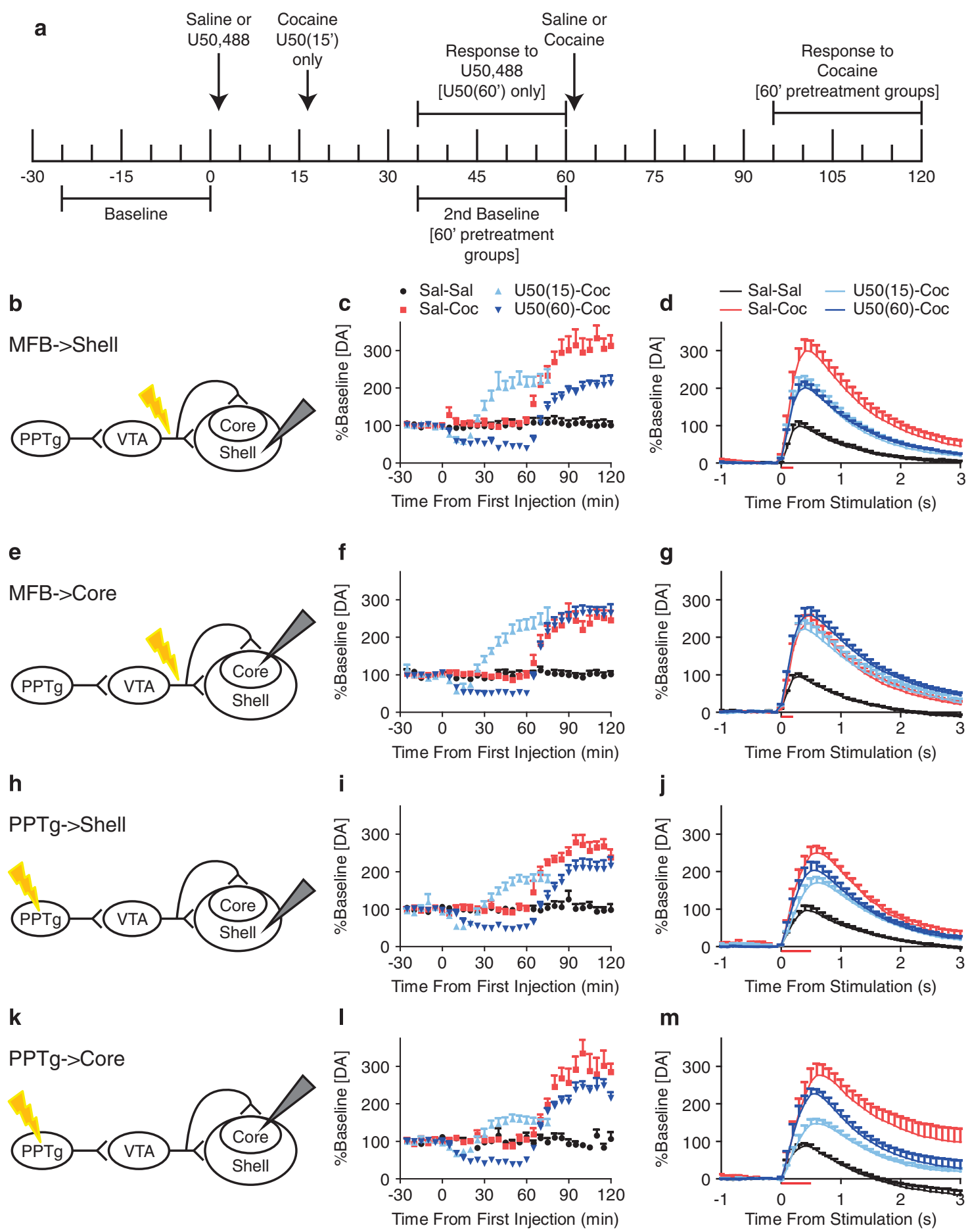
presynaptically drives burst firing in dopaminergic neurons in the VTA (Floresco et al, 2003; Zweifel et al, 2009). The extent of inhibition of evoked dopamine release caused by U50488 did not depend on the stimulation or recording site, suggesting that KOR regulates evoked dopamine release consistently in both pathways and in both projection sites (Figure 2a). Two-way ANOVA failed to find any effect of recording site $\left(\mathrm{F}_{(1,27)}=0.002972, P>0.05\right)$, stimulation site $\left(\mathrm{F}_{(1,27)}=0.07009, P>0.05\right)$, or any interaction between the two $\left(\mathrm{F}_{(1,27)}=2.449, P>0.05\right)$. Further, no effect of U50488 was found on $t_{1 / 2}$ for any combination of stimulation and recording site, with one-way ANOVA showing that recordings from MFB-shell $\left(\mathrm{F}_{(2,17)}=0.3507, P>0.05\right)$, MFB-core $\left(\mathrm{F}_{(2,19)}=0.003610, P>0.05\right)$, PPTg-shell $\left(\mathrm{F}_{(2,22)}=0.4929\right.$, $P>0.05)$, and PPTg-core $\left(\mathrm{F}_{(2,17)}=0.09620, P>0.05\right)$ all fail to show a significant effect of U50488 relative to the two saline-pretreated groups (data not shown). In addition, evoked dopamine responses were increased by cocaine to the same extent in both pathways and in both projection sites (Figure 2b). Two-way ANOVA failed to find any effect of recording site $\left(F_{(1,26)}=0.4639, P>0.05\right)$, stimulation site $\left(\mathrm{F}_{(1,26)}=0.01971, P>0.05\right)$, or any interaction between the two $\left(\mathrm{F}_{(1,26)}=4.130, P>0.05\right)$.

\section{Terminal Effects of KOR Activation Are Region-Dependent and Time-Independent, Whereas Somatodendritic Effects Are Both Region- and Time-Dependent}

As diagrammed in Figure 3a, mice were treated with U50488 or saline before cocaine or saline administration 15 or $60 \mathrm{~min}$ later. Evoked responses were stable during the $2 \mathrm{~h}$ course of the experiment for each pairing of stimulation and recording sites (black circles, saline-saline). Further, baseline levels of dopamine were similar for each treatment group within each combination of stimulation and recording site, demonstrating that observed differences between groups are not driven by basal differences in the concentration of evoked dopamine (Supplementary Figure 9). The time course of the responses to U50488 and cocaine is shown (Figure 3c, f, i and 1). MFB-evoked dopamine responses recorded from the NAc shell show that pretreatment with U50488 at either time point inhibited the response to cocaine relative to saline-pretreated animals (Figure $3 \mathrm{~d}$ ). This is confirmed by a two-way repeated-measures ANOVA comparing only the cocaine-treated groups before and after administration of cocaine (data not shown), which showed a main effect of time $\left(\mathrm{F}_{(1,15)}=154.4, P<0.0001\right)$ and of treatment before cocaine $\left(\mathrm{F}_{(2,15)}=12.98, P<0.001\right)$, but no interaction $\left(\mathrm{F}_{(2,15)}=2.492, P>0.05\right)$. One-way ANOVA showed a significant difference between the four groups after treatment with cocaine or saline (Figure $3 \mathrm{~d}, \mathrm{~F}_{(3,20)}=$ 16.45, $P<0.0001)$. Although cocaine increased the evoked dopamine response over baseline, subsequent Bonferroni post-hoc analysis demonstrated that prior administration of U50488 significantly inhibited the response to cocaine relative to saline-pretreated animals (Figure $3 \mathrm{~d}$ ) after pretreatment either $15 \mathrm{~min}(t=2.939, P<0.05)$ or $60 \mathrm{~min}$ $(t=3.806, P<0.01)$ prior.

By contrast, MFB-evoked dopamine responses recorded from the NAc core show that pretreatment with U50488 failed to alter the response to cocaine relative to saline-pretreated animals after pretreatment at either $15 \mathrm{~min}(t=0.4444, P>0.05)$ or $60 \mathrm{~min}$ ( $t=0.7870, P>0.05$; Figure $3 \mathrm{~g}$ ). A two-way repeatedmeasures ANOVA comparing only cocaine-treated groups before and after administration of cocaine (data not shown) showed a main effect of time $\left(\mathrm{F}_{(1,19)}=223.2, P<0.0001\right)$ and a significant interaction $\left(\mathrm{F}_{(2,19)}=3.538, P<0.05\right)$, but no main effect of treatment before cocaine $\left(\mathrm{F}_{(2,19)}=0.2956\right.$, $P>0.05)$. A one-way ANOVA showed a significant difference between the four groups after treatment with cocaine or saline (Figure $3 g, \mathrm{~F}_{(3,25)}=15.11, P<0.0001$ ). These results suggest that although the KOR regulation of dopamine release was comparable in core and shell, the interaction between $\mathrm{KOR}$ and cocaine results in greater inhibition in the shell. Surprisingly, there was no difference in the response between 15 and $60 \mathrm{~min}$ pretreatment in either region (shell: $t=0.2587, P>0.05$; core: $t=1.246$, $P>0.05)$, which suggests that the ability of KOR agonists to block cocaine CPP was not mediated by terminal effects on dopamine release in the NAc.

Similar results were evident after PPTg stimulation. Pretreatment with U50488 did not increase the amplitude of the cocaine response measured in either shell or core (Figure $3 \mathrm{j}$ and $\mathrm{m}$ ). A two-way repeated-measures ANOVA comparing only cocaine-treated groups before and after administration of cocaine in recordings from the NAc shell again showed a main effect of time $\left(F_{(1,22)}=241.8\right.$, $P<0.0001)$ and a main effect of treatment before cocaine $\left(\mathrm{F}_{(2,22)}=9.262, P<0.01\right)$, but no interaction $\left(\mathrm{F}_{(2,22)}=2.593\right.$, $P>0.05)$. One-way ANOVA performed on the evoked dopamine response measured in the NAc shell showed a significant difference between the four groups after treatment with cocaine or saline (Figure $3 \mathrm{j}, \mathrm{F}_{(3,28)}=15.22, P<0.0001$ ). Bonferroni post-hoc analysis showed that in the NAc shell, prior administration of U50488 reduced the response to cocaine relative to saline-pretreated animals after pretreatment at $15 \mathrm{~min}(t=3.482, P<0.01)$, with a similar trend seen after $60 \mathrm{~min}$ pretreatment $(t=2.288, P>0.05)$. Similar to MFB recordings, there was no separation between pretreatment at $15 \mathrm{~min}$ and at $60 \mathrm{~min}(\mathrm{t}=1.342, P>0.05)$.

Two-way repeated-measures ANOVA comparing the evoked dopamine response in the NAc core following PPTg stimulation from only cocaine-treated groups before and after administration of cocaine showed results slightly different from those observed following MFB stimulation: this analysis showed a main effect of time $\left(F_{(1,19)}=170.8\right.$, $P<0.0001)$, a main effect of treatment before cocaine $\left(\mathrm{F}_{(2,19)}=14.16, P<0.001\right)$, and a significant interaction $\left(\mathrm{F}_{(2,19)}=11.20, P<0.001\right)$. Intriguingly, this was the only combination of recording and stimulation site to show both a main effect of treatment before cocaine and an interaction between time and treatment. One-way ANOVA performed on the dopamine response in the NAc core following PPTg stimulation showed a significant difference between the four groups after treatment with cocaine or saline (Figure $3 \mathrm{~m}$, $\left.\mathrm{F}_{(3,24)}=20.08, P<0.0001\right)$. Interestingly, unlike the other combinations of stimulation and recording site, the PPTgcore combination showed a unique separation between the effects of U50488 at the two pretreatment times. Bonferroni post-hoc analysis shows that the response to cocaine after pretreatment $60 \mathrm{~min}$ prior was significantly greater than that seen after pretreatment at $15 \mathrm{~min}(t=2.972, P<0.05)$. Further, the response to cocaine $15 \mathrm{~min}$ after prior 
treatment with U50488 failed to induce significant elevations of dopamine relative to that seen in animals treated with saline alone $(t=2.054, P>0.05)$, unlike the responses seen after similar pretreatment in MFB-shell $(t=3.340, P<0.05)$, MFB-core $(t=4.789, P<0.001)$, and PPTg-shell $(t=2.958, P<0.05)$.

The difference in response between the MFB and PPTg stimulation sites suggests that action of kappa receptors in the somatodendritic region of the VTA dopaminergic neurons rather than at their terminals in the NAc may have a key role in the kappa opioid-induced potentiation of the cocaine response. To test this hypothesis, an experiment was performed in which after the baseline was established, current intensity was reduced to a level evoking [DA] half of that observed after $150 \mu \mathrm{A}$ stimulation. $T$-test found that reduction of baseline dopamine levels after reduction of stimulation current intensity was not significantly different from inhibition of dopamine induced by U50488 administration (data not shown; $t_{(10)}=0.1824, P>0.05$ ). One-way ANOVA performed on the dopamine response in the NAc core comparing this group to the other groups receiving cocaine showed a significant difference between the four groups after treatment with cocaine (Supplementary Figure $\left.10 \mathrm{~B}, \mathrm{~F}_{(3,24)}=9.253, P<0.001\right)$. Further, Bonferroni post-hoc analysis showed a significant reduction in the response to cocaine after reduction of stimulus intensity compared with saline-pretreated animals $(t=4.035, P<0.01)$ but a roughly equivalent response to that seen after $15 \mathrm{~min}$ pretreatment with U50488 $(t=0.3370, P>0.05)$. These findings support the hypothesis that the reduced response of PPTg-stimulated dopamine to cocaine observed in the NAc core after systemic U50488 administration is due to somatodendritic KOR activation inhibiting the firing of NAc core-projecting dopamine neurons.

\section{KOR-Induced Potentiation of Cocaine Reward can be Modeled by the Altered Baseline of Evoked Dopamine Responses}

During CPP training, mice are placed in the preference chamber directly following administration of cocaine. As such, it seems likely that the relevant component of the evoked dopamine response is that immediately preceding the cocaine injection. When we reanalyze the evoked dopamine response for each group using the baseline immediately before cocaine injection, the dopamine responses in the NAc all showed broadly similar results (Figure $4 a-d$ ). For MFB-stimulated dopamine responses recorded in the NAc shell, one-way ANOVA showed a significant effect of treatment (Figure 4a; $\mathrm{F}_{(3,20)}=24.33, P<0.0001$ ). Pretreatment with U50488 60 min before cocaine led to significantly greater elevations in evoked dopamine response than those observed in saline-pretreated animals $(t=3.762, P<0.01)$ or animals pretreated with $\mathrm{U} 50488$ at $15 \mathrm{~min}(t=3.972$, $P<0.01)$. However, pretreatment with U50488 15 min before cocaine showed no difference from saline-pretreated animals ( $t=0.6211, P>0.05)$ and led to increases in dopamine response significantly different from that seen in animals treated with saline alone $(t=3.345, P<0.05)$.

MFB-stimulated dopamine recorded from the NAc core showed a similar and also significant effect of cocaine or saline (Figure $4 \mathrm{~b} ; \mathrm{F}_{(3,25)}=56.68, P<0.0001$ ). Pretreatment with U50488 $60 \mathrm{~min}$ before cocaine led to relatively greater elevations in dopamine than those observed in saline-pretreated animals $(t=7.864, P<0.001)$ or animals pretreated with $\mathrm{U} 50488$ at $15 \mathrm{~min}(t=7.177, P<0.001)$. However, pretreatment with U50488 at $15 \mathrm{~min}$ showed no difference from saline-pretreated animals $(t=0.6648$, $P>0.05)$ and increases in dopamine significantly greater than that seen in animals treated with saline alone $(t=5.492, P<0.001)$ were recorded.

PPTg-stimulated dopamine recorded from the NAc shell showed a significant effect $\left(\mathrm{F}_{(3,28)}=45.52, \quad P<0.0001\right)$ similar to that observed after MFB stimulation in either NAc subregion (Figure 4c). Pretreatment with U50488 $60 \mathrm{~min}$ before cocaine led to relatively greater elevations in dopamine than those observed in saline-pretreated animals $(t=5.295, P<0.001)$ or animals pretreated with $\mathrm{U} 50488$ at $15 \mathrm{~min}(t=7.198, P<0.001)$. However, pretreatment with U50488 at $15 \mathrm{~min}$ showed no difference from saline-pretreated animals $(t=2.245, P>0.05)$ and led to increases in dopamine significantly different from that seen in animals treated with saline alone $(t=3.949, P<0.01)$.

PPTg-stimulated dopamine release recorded in the NAc core also showed a significant effect $\left(\mathrm{F}_{(3,24)}=36.84\right.$, $P<0.0001$ ) of treatment (Figure $4 \mathrm{~d}$ ). Similar to the results seen with the other stimulation-recording pairings, Bonferroni post-hoc analysis showed that $60 \mathrm{~min}$ pretreatment with U50488 led to significantly greater increases in evoked dopamine relative to animals treated with saline before cocaine $(t=5.566, P<0.001)$ and relative to animals treated with U50488 $15 \mathrm{~min}$ before cocaine $(t=8.345, P<0.001)$. However, Bonferroni post-hoc analyses also showed that the response to cocaine was significantly smaller after pretreatment with U50488 15 min before cocaine compared with pretreatment with saline $(t=3.002, P<0.05)$. Further, cocaine administered $15 \mathrm{~min}$ after U50488 failed to elevate NAc core dopamine to levels significantly greater than animals treated with only saline $(t=2.103, P>0.05)$, whereas animals that received cocaine $60 \mathrm{~min}$ after either saline or U50488 both showed significant increases relative to saline-only animals (sal-coc: $t=4.883, P<0.001$; U50(60)-coc: $t=9.773, P<0.001$ ). Finally, when using one-way ANOVA to compare saline- and U50488-pretreated animals to animals receiving a reduction in stimulus current, a similar pattern emerged (Figure 5a, F(3, $24)=18.99, \quad P<0.0001)$. Bonferroni post-hoc analysis comparing this alternate baseline showed no difference between saline-pretreated animals and animals receiving a reduction in stimulus before cocaine $(t=0.9607, P>0.05)$. This confirms the results of the experiment shown in Supplementary Figure 7, demonstrating that for PPTg stimulation the response to cocaine as percent baseline is independent of the stimulus intensity. As such, similar to saline-pretreated animals, animals receiving a reduced stimulus current showed a significantly greater response to cocaine than animals pretreated with U50488 $15 \mathrm{~min}$ before cocaine $(t=3.450, P<0.01)$ and a significantly weaker response to cocaine than animals treated with U50488 $60 \mathrm{~min}$ after U50488 $(t=3.764, P<0.01)$. The unique difference between the responses to 15 and $60 \mathrm{~min}$ pretreatment suggests that NAc core-projecting dopaminergic neurons have a key role in the ability of KOR agonists to both decrease and increase the rewarding properties of cocaine. 
a

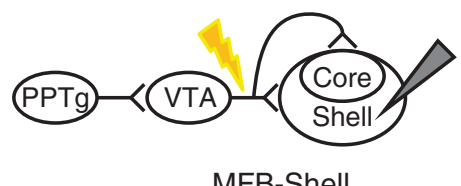

MFB-Shell
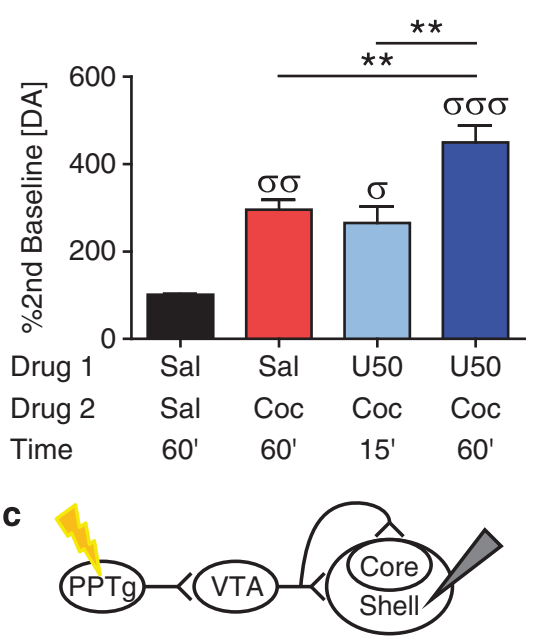

PPTg-Shell

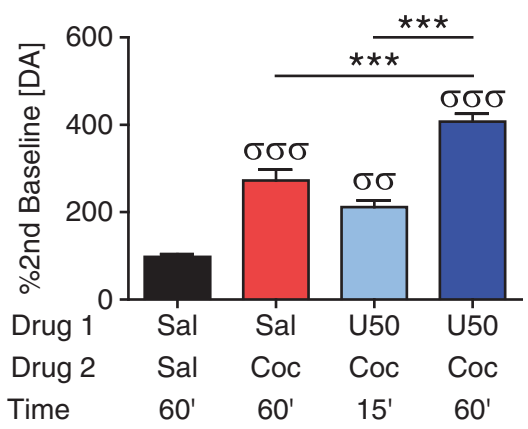

b

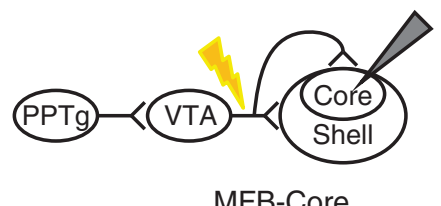

MFB-Core

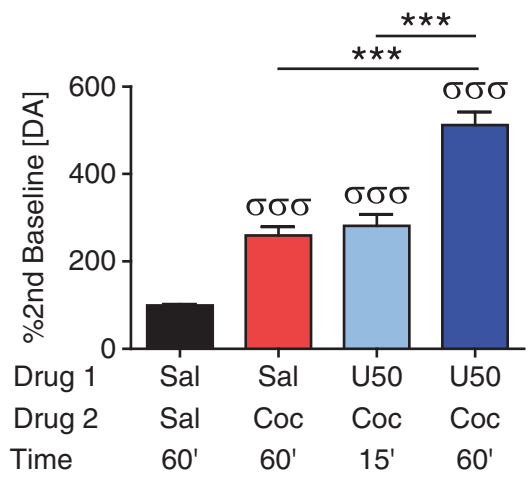

d

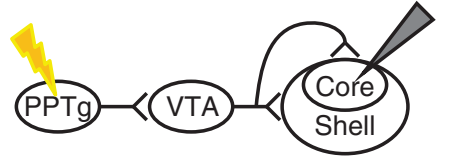

PPTg-Core

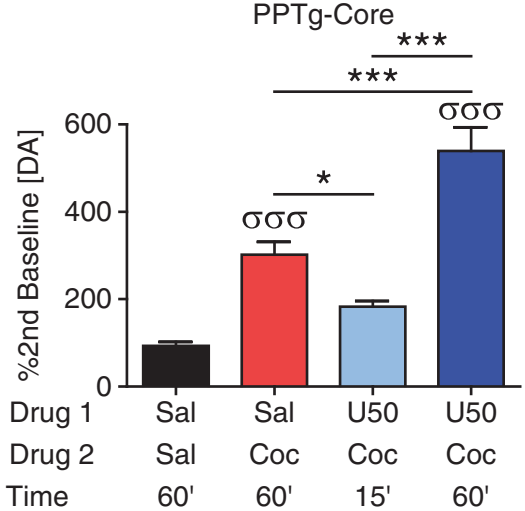

Figure 4 Using the time before cocaine administration as a baseline shows that 60 min pretreatment with U50488 consistently potentiates cocaine's ability to elevate dopamine concentration regardless of stimulation or recording site. By contrast, only PPTg-stimulated dopamine release recorded from the NAc core shows a block of the response to cocaine after 15 min pretreatment with U50488. (a) 60 min pretreatment with U50488 before cocaine potentiated MFB-evoked dopamine recorded from the NAc shell relative to both saline-pretreated animals and I 5 min pretreatment with U50488 before cocaine $(n=4-8)$. (b) 60 min pretreatment with U50488 before cocaine potentiated MFB-evoked dopamine recorded from the NAc core relative to both saline-pretreated animals and 15 min pretreatment with U50488 before cocaine $(n=7-9)$. (c) 60 min pretreatment with U50488 before cocaine potentiated PPTg-evoked dopamine recorded from the NAc shell relative to both saline-pretreated animals and I5 min pretreatment with U50488 before cocaine $(n=7-9)$. (d) 60 min pretreatment with U50488 before cocaine potentiated PPTg-evoked dopamine recorded from the NAc core relative to both saline-pretreated animals and 15 min pretreatment with U50488 before cocaine. Further, I 5 min pretreatment with U50488 significantly inhibited the response to cocaine relative to saline-pretreated animals; and cocaine after 15 min pretreatment with U50488 failed to alter dopamine levels significantly relative to animals treated with saline alone $(n=6-8)$. ${ }^{*} P<0.05$, ${ }^{*} * P<0.01$, ${ }^{*} * * P<0.00$ I between groups as marked; ${ }^{\sigma} P<0.05,{ }^{\sigma \sigma} P<0.0$ I, ${ }^{\sigma \sigma \sigma} P<0.00$ I labeled group vs saline-saline. Error bars represent SEM.

\section{Analysis of the Interaction Between U50488 and Cocaine by Recording and Stimulation Sites Reveals Different Effects at Different Pretreatment Times}

The difference between U50488 pretreatment 15 and $60 \mathrm{~min}$ before cocaine was also evident when the MFB- and PPTg-stimulated responses were directly compared (Figure 5). Two-way ANOVA showed that pretreatment with U50488 15 min before cocaine induced a significant effect of stimulation site (Figure $5 \mathrm{~b}, \mathrm{~F}_{(1,22)}=9.823, P<0.01$ ), whereas showing no effect of recording site $\left(F_{(1,22)}=0.03423\right.$, $P>0.05)$ and no interaction $\left(\mathrm{F}_{(1,22)}=1.302, P>0.05\right)$. As described previously, a two-way ANOVA showed that in saline-pretreated animals the response to cocaine was consistent across recording and stimulation site (Figure $2 \mathrm{~b}$ ); as such, we would expect any effect of recording or stimulation site seen in U50488-pretreated animals to be a result of KOR activation. These results show that the effect of U50488 was greater on the PPTg-stimulated response than on MFB, suggesting that there was an effect of somatodendritic KOR activation at this time point that is only evident in the presence of cocaine.

By contrast, two-way ANOVA showed that pretreatment with U50488 $60 \mathrm{~min}$ before cocaine induced a significant 
a

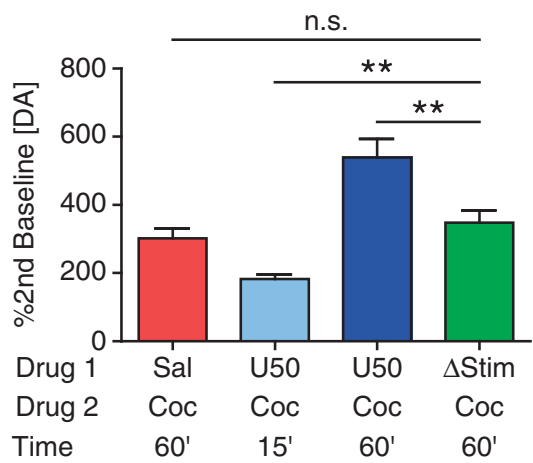

C

$\mathrm{U} 50,488,60^{\prime}$

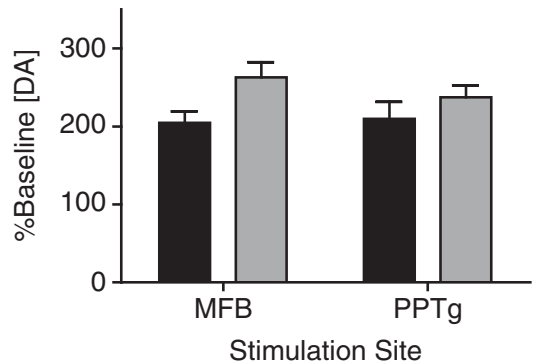

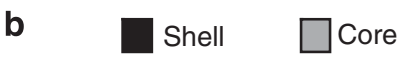

U50,488, 15

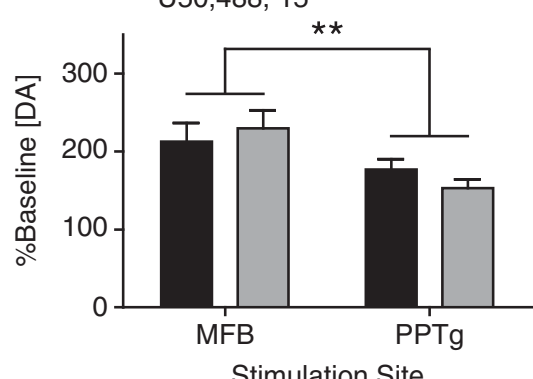

Stimulation Site

d

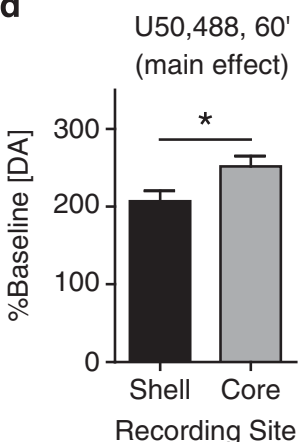

Figure 5 (a) The potentiation by cocaine of the dopamine response evident after U50488 was not equivalent to simply reducing the stimulus intensity. $(n=6-8)$. (b-d) Analysis by pretreatment time shows that after 15 min pretreatment with U 50488 , the response to cocaine is determined by stimulation site. By contrast, after 60 min pretreatment with U50488, the response to cocaine is determined by recording site. (b) 15 min after pretreatment with U50488, the response of PPTg-stimulated dopamine to cocaine is significantly inhibited relative to MFB-stimulated dopamine $(n=4-8)$. (c) 60 min after pretreatment with U50488, the response of PPTg-stimulated dopamine to cocaine was significantly inhibited in the NAc shell relative to the NAc core $(n=6-9)$. (d) The main effect of the two-way ANOVA shown in panel c. n.s. $P>0.05$, $* P<0.05$, $* * P<0.0$ l between groups as marked. Error bars represent SEM.

effect of recording site (Figure $5 \mathrm{c}$ and $\mathrm{d}, \mathrm{F}_{(1,27)}=5.102$, $P<0.05)$ but no effect of stimulation site $\left(\mathrm{F}_{(1,27)}=0.2767\right.$, $P>0.05)$ and no interaction $\left(\mathrm{F}_{(1,27)}=0.6487, P>0.05\right)$. The presence of a main effect of stimulation site in $15 \mathrm{~min}$, but not $60 \mathrm{~min}$, pretreated animals supports the interpretation that there was a time-dependent somatodendritic effect of KOR activation on the response to cocaine. The presence of a main effect of recording site in $60 \mathrm{~min}$-pretreated animals suggests that there was a region-dependent effect underlying the inhibition of the response to cocaine seen in shell, but not in core, which was dependent on activation of terminal KORs. Further, the presence of a main effect of recording site in the 60 min U50488-pretreated animals, but not in saline-pretreated animals, demonstrates that the presence of an inhibited response to cocaine in shell, but not in core (as clearly seen after MFB-stimulated dopamine release), was not due to a ceiling effect in the overall response to cocaine in these two brain regions.

\section{DISCUSSION}

The principal findings of this study are first, that KORinduced potentiation of cocaine reward can be modeled by KOR-induced changes in NAc dopamine at the time of cocaine administration. Second, that the ability of KOR activation to block cocaine reward cannot be explained solely by terminal inhibition of dopamine release in the NAc, but must also incorporate effects of somatodendritic
KOR activation on dopaminergic neurons. Third, that activation of terminal KOR on dopaminergic neurons significantly inhibits the response to cocaine in NAc shell but not in NAc core. Fourth, our findings suggest a key role for dopaminergic neurons that project to the NAc core in KOR-mediated effects on cocaine reward.

\section{KOR Agonist-Induced Block of Cocaine Reward is Not Mediated Through Terminal Inhibition of NAc Dopamine Release}

Acute pretreatment (5-20 min) with KOR agonists blocks the induction of cocaine CPP (McLaughlin et al, 2006; Zhang et al, 2004a, 2004b) and the reward-sensitizing properties of cocaine (Shippenberg et al, 1996), as well as blocking cocaine-induced decreases in ICSS thresholds (Tomasiewicz et al, 2008). Previous attempts to explain this phenomenon have focused on terminal effects of KOR activation in dopaminergic neurons (Carlezon and Thomas, 2009; Carroll and Carlezon, 2013; Tejeda et al, 2012). This is consistent with the knowledge that although both intra-NAc and intra-VTA microinjection of U50488 result in conditioned place aversion (Bals-Kubik et al, 1993), intra-NAc but not intra-VTA perfusion of U69593 induces a reduction in NAc dopamine (Devine et al, 1993; Margolis et al, 2006; Spanagel et al, 1992). Similarly, our results show that a consistent inhibition of basal dopamine concentrations was seen in both subregions regardless of whether MFB or PPTg 
are stimulated, suggesting that somatodendritic KOR activation did not induce an additive reduction in dopamine release above and beyond terminal inhibition of release. This is despite the fact that previous experiments have shown that in mice NAc-projecting dopaminergic neurons are directly inhibited by the KOR agonist U69593 (Ford et al, 2006), presumably via activation of G-protein coupled inwardly rectifying potassium channels (Margolis et al, 2003). However, our results also show a time-dependent reduction in the ability of cocaine to increase PPTg-evoked but not MFB-evoked NAc dopamine after pretreatment with U50488. Further, our results show that 15 min pretreatment with U50488 inhibits the response of PPTg-evoked dopamine to cocaine in the NAc core in a manner similar to that seen after reducing the intensity of the stimulus current. This suggests that cocaine administration exposes an obscured somatodendritic component of KOR activation in NAc-projecting dopaminergic neurons.

Activation of Terminal KOR on Dopaminergic Neurons Inhibits the Response to Cocaine in NAc Shell but Not Core

Intriguingly, our experiments found that although pretreatment with U50488 inhibited the response of MFB-stimulated dopamine to cocaine in the NAc shell, no such effect was seen in the NAc core. This suggests that activation of KORs on dopamine terminals in the NAc shell and the NAC core lead to activation of different signal transduction pathways. One mediator that could potentially have a role is p38 MAPK, which has a key role in mediating the stressinduced dysphoric properties of KOR activation. U50488 CPA and swim stress-induced increases in immobility are blocked by i.c.v. administration of the p38 inhibitor SB203580 (Bruchas et al, 2007). Activation of p38 MAPK by anisomycin has been shown to inhibit dopamine uptake in transfected CHO cells (Zhu et al, 2005), and inhibition of p38 by SB202190 has been shown to increase the Vmax of the dopamine transporter (DAT) after mutation of multiple N-terminal serine phosphoacceptor sites (Lin et al, 2003). P38 MAPK is also capable of phosphorylating threonine 53 in the N-terminal domain of DAT (Gorentla et al, 2009), although mutations intended to block phosphorylation at this site lead to a reduction in DAT Vmax, suggesting that phosphorylation would increase dopamine clearance (Foster et al, 2012). Further, previous research has demonstrated that KOR-induced activation of p38 MAPK can lead to target-specific changes in monoamine clearance, as repeated forced swim stress induces increases in SERT surface expression in terminals in the ventral striatum but not dorsal striatum, prefrontal-cortex, hippocampus, amygdala, or dorsal raphe (Schindler et al, 2012).

Also consistent with the idea that terminal KOR activation may act to differently regulate the response to cocaine in different brain regions, a previous experiment has shown using microdialysis that direct perfusion of the KOR agonist dynorphin $\mathrm{A}(1-17)$ into the dorsal striatum $5 \mathrm{~min}$ before systemic cocaine-blocked cocaine-induced elevations of dopamine in the same region (Zhang et al, 2004a). This is in contrast with our data, which shows that KOR agonists inhibit (but do not block) cocaine-induced elevations of dopamine in the NAc shell and fail to alter the response to cocaine in the NAc core after MFB stimulation. However, data collected with microdialysis will primarily reflect changes in tonic dopamine release, whereas the increased temporal resolution of FSCV renders it more sensitive to individual phasic responses (Robinson et al, 2003). As such, it is also possible that KOR regulates tonic release by different mechanisms than phasic release events.

\section{NAc Core-Projecting Dopaminergic Neurons Are Uniquely Responsive to KOR Agonist Pretreatment Time}

Our data show that although U50488 administration inhibits the response of mesolimbic dopamine in the NAc shell to cocaine, after the 15 min pretreatment, cocaine still elevates NAc shell dopamine relative to animals treated with saline alone regardless of stimulation site. By contrast, in the NAc core, the response of PPTg-stimulated dopamine to cocaine is inhibited by $15 \mathrm{~min}$ pretreatment with U50488 relative to both saline-pretreated and $60 \mathrm{~min}$ U50488-pretreated animals, while also blocking cocaine from elevating dopamine to levels significantly greater than animals treated with saline alone regardless of baseline used. This suggests that NAc core-projecting dopaminergic neurons may have a unique role in mediating stress-induced modulation of the magnitude of drug reward. This finding is seemingly inconsistent with theories that dopaminergic projections to the medial NAc shell have a key role in learning stimulusoutcome association, whereas dopaminergic projections to the lateral NAc-including the core-are key to generating or selecting appropriate responses to conditioned responses (Ikemoto, 2007). However, it is potentially consistent with observations that the NAc core has a key role in drug seeking, with activation in this region being required for both cocaine-primed and stress-primed reinstatement to drug self-administration, whereas activation of the shell is required only for stress-induced reinstatement (McFarland and Kalivas, 2001; McFarland et al, 2004). In addition, the fact that the NAc core seems to have a key role in both acquisition/consolidation and expression of responses to conditioned rewards (Ikemoto, 2007) is consistent with the observation that both stress and KOR agonists can potentiate drug reward when administered prior either to drug training or to a place preference test (McLaughlin et al, 2003, 2006; Schindler et al, 2010). As such, this suggests that future experiments examining interactions between stress and drug reward should focus on this subregion as a site for integrating these signals.

\section{MFB and PPTg Stimulation can be Used to Isolate Separate Contributions to Dopamine Signaling}

Electrical stimulation of the MFB directly activates dopamine fibers and elicits terminal release of dopamine; by contrast, electrical stimulation of the PPTg induces glutamate and acetylcholine release at terminals in the VTA, leading to a selective increase in burst firing of dopaminergic neurons and terminal release of dopamine, which is dependent on activation of NMDA receptors on VTA dopamine neurons (Floresco et al, 2003; Zweifel et al, 2009). Phasic dopamine release induced by burst firing is more responsive to dopamine uptake inhibitors than tonic release 
(Floresco et al, 2003); and phasic release has been proposed to have a unique role in the rewarding properties of drugs of abuse (Wanat et al, 2009). The PPTg itself encodes reward information in a context-dependent manner (Norton et al, 2011). Given that KOR agonists can presynaptically inhibit glutamate release on to VTA dopaminergic neurons (Margolis et al, 2005), it is possible that the results of experiments examining PPTg-stimulated dopamine release reflect effects of KOR activation on PPTg axon terminals. However, as the Allen Mouse Brain Atlas fails to show KOR mRNA in the vicinity of PPTg nuclei (Lein et al, 2007), this suggests that the results are more likely mediated by direct KOR effects on dopaminergic neurons. This is also consistent with the prior observation that KOR expression on dopaminergic neurons is required for KOR-induced inhibition of NAc dopamine (Chefer et al, 2013), indicating that KOR activation on VTA-projecting terminals is not sufficient to alter dopamine signaling at the level of the NAc. Further, this would indicate that the time-dependent nature of the response to cocaine after U50488 pretreatment, seen in PPTgstimulated dopamine release but not in MFB-stimulated dopamine release, is a response specific to KOR activation in the somatodendritic compartment of dopaminergic neurons.

\section{CONCLUSION}

Our results from recordings of MFB-stimulated dopamine release show that activation of terminal KORs alter the response to cocaine in a manner that is dependent on NAcsubregion but not on time, with recordings from the shell but not core showing an inhibited response to cocaine after pretreatment with the KOR agonist U50488 at both time points. However, in both cases the response to cocaine still elevates dopamine concentrations to levels greater than that seen in animals treated with saline alone. Our results from recordings of PPTg-stimulated dopamine release show that activation of somatodendritic KORs alter the response to cocaine in a manner that is primarily dependent on time and potentially partially dependent on subregion, with recordings $15 \mathrm{~min}$ but not $60 \mathrm{~min}$ after pretreatment with U50488 showing an inhibited response to cocaine. In particular, recordings from the core $15 \mathrm{~min}$ after U50488 pretreatment fail to show a significant increase in dopamine relative to animals treated with saline alone, whereas animals pretreated with U50488 $60 \mathrm{~min}$ before cocaine fail to show any difference from animals pretreated with saline $60 \mathrm{~min}$ before cocaine. Further analysis indicates that tracking the response to cocaine at the time of cocaine administration shows that the response of PPTg-stimulated dopamine release in the NAc core mirrors the behavioral response, suggesting that the subpopulation of VTA dopaminergic neurons that project to the core may have a unique role in the ability of stress to increase the rewarding properties of psychostimulants and further suggesting that behavioral and pharmacological manipulations of dopamine must incorporate an understanding of dopamine signaling as a dynamic phenomenon.

\section{FUNDING AND DISCLOSURE}

The work was supported by USPHS awards from NIDA: RO1DA030074 (CC), KO5DA020570 (CC), T32DA07278
(JME), F31DA0308932 (JME). The authors have no conflict of interest.

\section{ACKNOWLEDGEMENTS}

We thank Dr Scott B Evans for help with FSCV recording equipment setup and Mr Chad Zietz for help with histology.

\section{REFERENCES}

Bals-Kubik R, Ableitner A, Herz A, Shippenberg TS (1993). Neuroanatomical sites mediating the motivational effects of opioids as mapped by the conditioned place preference paradigm in rats. J Pharmacol Exp Ther 264: 489-495.

Bruchas MR, Land BB, Aita M, Xu M, Barot SK, Li S et al (2007). Stress-induced p38 mitogen-activated protein kinase activation mediates kappa-opioid-dependent dysphoria. J Neurosci 27: 11614-11623.

Bruchas MR, Land BB, Chavkin C (2010). The dynorphin/kappa opioid system as a modulator of stress-induced and proaddictive behaviors. Brain Res 1314: 44-55.

Bruijnzeel AW (2009). kappa-Opioid receptor signaling and brain reward function. Brain Res Rev 62: 127-146.

Carlezon WA, Thomas MJ (2009). Biological substrates of reward and aversion: a nucleus accumbens activity hypothesis. Neuropharmacology 56(Suppl 1)): 122-132.

Carroll FI, Carlezon WA (2013). Development of $\kappa$ Opioid Receptor Antagonists. J Med Chem 56: 2178-2195.

Chefer VI, Bäckman CM, Gigante ED, Shippenberg TS (2013). Kappa opioid receptors on dopaminergic neurons are necessary for kappa-mediated place aversion. Neuropsychopharmacology 38: 2623-2631.

Di, Chiara G, Imperato A (1988). Drugs abused by humans preferentially increase synaptic dopamine concentrations in the mesolimbic system of freely moving rats. Proc Natl Acad Sci USA 85: 5274-5278.

DeFrank RS, Jenkins CD, Rose RM (1987). A longitudinal investigation of the relationships among alcohol consumption, psychosocial factors, and blood pressure. Psychosom Med 49: 236-249.

Devine DP, Leone P, Pocock D, Wise RA (1993). Differential involvement of ventral tegmental mu, delta and kappa opioid receptors in modulation of basal mesolimbic dopamine release: in vivo microdialysis studies. J Pharmacol Exp Ther 266: 1236-1246.

Floresco SB, West AR, Ash B, Moore H, Grace AA (2003). Afferent modulation of dopamine neuron firing differentially regulates tonic and phasic dopamine transmission. Nat Neurosci 6: 968-973.

Ford CP, Mark GP, Williams JT (2006). Properties and opioid inhibition of mesolimbic dopamine neurons vary according to target location. J Neurosci 26: 2788-2797.

Foster JD, Yang J-W, Moritz AE, Challasivakanaka S, Smith MA, Holy M et al (2012). Dopamine transporter phosphorylation site threonine 53 regulates substrate reuptake and amphetaminestimulated efflux. J Biol Chem 287: 29702-29712.

Goeders NE, Guerin GF (1994). Non-contingent electric footshock facilitates the acquisition of intravenous cocaine self-administration in rats. Psychopharmacology (Berl) 114: 63-70.

Gorentla BK, Moritz AE, Foster JD, Vaughan RA (2009). Prolinedirected phosphorylation of the dopamine transporter N-terminal domain. Biochemistry 48: 1067-1076.

Hyland B, Reynolds JN, Hay J, Perk C, Miller R (2002). Firing modes of midbrain dopamine cells in the freely moving rat. Neuroscience 114: 475-492.

Ikemoto S (2007). Dopamine reward circuitry: two projection systems from the ventral midbrain to the nucleus accumbensolfactory tubercle complex. Brain Res Rev 56: 27-78. 
Knoll AT, Carlezon WA (2010). Dynorphin, stress, and depression. Brain Res 1314: 56-73.

Lein ES, Hawrylycz MJ, Ao N, Ayres M, Bensinger A, Bernard A et al (2007). Genome-wide atlas of gene expression in the adult mouse brain. Nature 445: 168-176.

Lin Z, Zhang P-W, Zhu X, Melgari J-M, Huff R, Spieldoch RL et al (2003). Phosphatidylinositol 3-kinase, protein kinase C, and MEK1/2 kinase regulation of dopamine transporters (DAT) require N-terminal DAT phosphoacceptor sites. J Biol Chem 278: 20162-20170.

Mantsch JR, Vranjkovic O, Twining RC, Gasser PJ, McReynolds JR, Blacktop JM (2014). Neurobiological mechanisms that contribute to stress-related cocaine use. Neuropharmacology 76 (Pt B): 383-934.

Margolis EB, Hjelmstad GO, Bonci A, Fields HL (2003). Kappaopioid agonists directly inhibit midbrain dopaminergic neurons. J Neurosci 23: 9981-9986.

Margolis EB, Hjelmstad GO, Bonci A, Fields HL (2005). Both kappa and mu opioid agonists inhibit glutamatergic input to ventral tegmental area neurons. J Neurophysiol 93: 3086-3093.

Margolis EB, Lock H, Chefer VI, Shippenberg TS, Hjelmstad GO, Fields HL (2006). Kappa opioids selectively control dopaminergic neurons projecting to the prefrontal cortex. Proc Natl Acad Sci USA 103: 2938-2942.

McFarland K, Davidge SB, Lapish CC, Kalivas PW (2004). Limbic and motor circuitry underlying footshock-induced reinstatement of cocaine-seeking behavior. J Neurosci 24: 1551-1560.

McFarland K, Kalivas PW (2001). The circuitry mediating cocaineinduced reinstatement of drug-seeking behavior. J Neurosci 21: 8655-8663.

McLaughlin JP, Land BB, Li S, Pintar JE, Chavkin C (2006). Prior activation of kappa opioid receptors by U50488 mimics repeated forced swim stress to potentiate cocaine place preference conditioning. Neuropsychopharmacology 31: 787-794.

McLaughlin JP, Marton-Popovici M, Chavkin C (2003). Kappa opioid receptor antagonism and prodynorphin gene disruption block stress-induced behavioral responses. J Neurosci 23: 5674-5683.

Miller PM, Hersen M, Eisler RM, Hilsman G (1974). Effects of social stress on operant drinking of alcoholics and social drinkers. Behav Res Ther 12: 67-72.

Norton ABW, Jo YS, Clark EW, Taylor CA, Mizumori SJY (2011). Independent neural coding of reward and movement by pedunculopontine tegmental nucleus neurons in freely navigating rats. Eur J Neurosci 33: 1885-1896.

Piazza PV, Deminiere JM, Moal M, le, Simon H (1990). Stress- and pharmacologically-induced behavioral sensitization increases vulnerability to acquisition of amphetamine self-administration. Brain Res 514: 22-26.

Pomerleau CS, Pomerleau OF (1987). The effects of a psychological stressor on cigarette smoking and subsequent behavioral and physiological responses. Psychophysiology 24: 278-285.

Robinson DL, Venton BJ, Heien MLA V, Wightman RM (2003). Detecting subsecond dopamine release with fast-scan cyclic voltammetry in vivo. Clin Chem 49: 1763-1773.

Schenk S, Shippenberg TS, Partridge B (1999). U69593, a kappaopioid agonist, decreases cocaine self-administration and decreases cocaine-produced drug-seeking. Psychopharmacology (Berl) 144: 339-346.

Schindler AG, Li S, Chavkin C (2010). Behavioral stress may increase the rewarding valence of cocaine-associated cues through a dynorphin/kappa-opioid receptor-mediated mechanism without affecting associative learning or memory retrieval mechanisms. Neuropsychopharmacology 35: 1932-1942.

Schindler AG, Messinger DI, Smith JS, Shankar H, Gustin RM, Schattauer SS et al (2012). Stress produces aversion and potentiates cocaine reward by releasing endogenous dynorphins in the ventral striatum to locally stimulate serotonin reuptake. J Neurosci 32: 17582-17596.

Shippenberg TS, Bals-Kubik R, Herz A (1993). Examination of the neurochemical substrates mediating the motivational effects of opioids: role of the mesolimbic dopamine system and D-1 vs D-2 dopamine receptors. J Pharmacol Exp Ther 265: 53-59.

Shippenberg TS, Chefer VI, Zapata A, Heidbreder CA (2001). Modulation of the behavioral and neurochemical effects of psychostimulants by kappa-opioid receptor systems. Ann NY Acad Sci 937: 50-73.

Shippenberg TS, Herz A (1988). Motivational effects of opioids: influence of D-1 versus D-2 receptor antagonists. Eur J Pharmacol 151: 233-242.

Shippenberg TS, LeFevour A, Heidbreder C (1996). Kappa-opioid receptor agonists prevent sensitization to the conditioned rewarding effects of cocaine. J Pharmacol Exp Ther 276: 545-554.

Smith JS, Schindler AG, Martinelli E, Gustin RM, Bruchas MR, Chavkin C (2012). Stress-induced activation of the dynorphin/ $\kappa-$ opioid receptor system in the amygdala potentiates nicotine conditioned place preference. J Neurosci 32: 1488-1495.

Spanagel R, Herz A, Shippenberg TS (1992). Opposing tonically active endogenous opioid systems modulate the mesolimbic dopaminergic pathway. Proc Natl Acad Sci USA 89: 2046-2050.

Tejeda HA, Counotte DS, Oh E, Ramamoorthy S, Schultz-Kuszak KN, Bäckman CM et al (2013). Prefrontal cortical kappa-opioid receptor modulation of local neurotransmission and conditioned place aversion. Neuropsychopharmacology 38: 1770-1779.

Tejeda HA, Shippenberg TS, Henriksson R (2012). The dynorphin/ $\kappa$-opioid receptor system and its role in psychiatric disorders. Cell Mol Life Sci 69: 857-896.

Tomasiewicz HC, Todtenkopf MS, Chartoff EH, Cohen BM, Carlezon WA (2008). The kappa-opioid agonist U69 593 blocks cocaine-induced enhancement of brain stimulation reward. Biol Psychiatry 64: 982-988.

Wanat MJ, Willuhn I, Clark JJ, Phillips PEM (2009). Phasic dopamine release in appetitive behaviors and drug addiction. Curr Drug Abuse Rev 2: 195-213.

Wise RA, Morales M (2010). A ventral tegmental CRF-glutamatedopamine interaction in addiction. Brain Res 1314: 38-43.

Zhang Y, Butelman ER, Schlussman SD, Ho A, Kreek MJ (2004a). Effect of the endogenous kappa opioid agonist dynorphin $\mathrm{A}(1-17)$ on cocaine-evoked increases in striatal dopamine levels and cocaine-induced place preference in C57BL/6J mice. Psychopharmacology (Berl) 172: 422-429.

Zhang Y, Butelman ER, Schlussman SD, Ho A, Kreek MJ (2004b). Effect of the kappa opioid agonist R-84760 on cocaine-induced increases in striatal dopamine levels and cocaine-induced place preference in C57BL/6J mice. Psychopharmacology (Berl) 173: $146-152$.

Zhu C-B, Carneiro AM, Dostmann WR, Hewlett WA, Blakely RD (2005). p38 MAPK activation elevates serotonin transport activity via a trafficking-independent, protein phosphatase 2A-dependent process. J Biol Chem 280: 15649-15658.

Zweifel LS, Parker JG, Lobb CJ, Rainwater A, Wall VZ, Fadok JP et al (2009). Disruption of NMDAR-dependent burst firing by dopamine neurons provides selective assessment of phasic dopaminedependent behavior. Proc Natl Acad Sci USA 106: 7281-7288.

Supplementary Information accompanies the paper on the Neuropsychopharmacology website (http://www.nature.com/npp) 